\title{
Technical Innovation Path and Performance of Self-owned Brand Automobiles
}

\author{
Shu-zhu JIANG \\ Economic School of Shandong Institute of Business and Technology, Yantai, Shandong, China
}

Keywords: Technology innovation, Product quality, Transnational mergers and acquisitions.

\begin{abstract}
Taking the profit of automotive enterprises in 2016 for example to analyze the importance of technology innovation. It is thought that the ability of technology innovation played an important role in profit improvement for automotive enterprises; independent innovation may only bring some leading edge in self-owned brands; foreign automotive enterprises refuse to transfer key technology; our companies can earn foreign automotive enterprises' technology resources by transnational M\&A. Therefore, in order to enhance the ability of technology innovation for self-owned brands, our government should strengthen the intelligent property protection and punish severely the infringement; the enterprises should obtain foreign advanced technology through cross-border mergers and acquisitions, at the same time integrate into the global value chain.
\end{abstract}

\section{自主品牌汽车的技术创新路径与绩效}

\author{
姜书竹 \\ 山东工商学院 经济学院, 山东 烟台, 中国
}

关键词：汽车企业；技术创新；跨国并购

摘要：以2016年上市车企利润增长情况为例, 分析技术创新的重要性。技术创新能力对车企 业绩提升起到了重要作用; 直接实施自主创新只能获得相对于其他自主品牌的些许领先优势; 国外车企也不可能直接转让核心技术; 只有通过跨国并购才能获得国外车企的技术资源。因 此, 要提高自主品牌技术创新能力, 还需政府加强知识产权保护、严惩侵权行为; 车企则可 通过跨国并购获得国外先进技术，同时积极融入全球价值链。

\section{1. 引言}

改革开发以来，市场经济得到了快速发展，除了少数涉及国计民生、需求弹性较小或无 弹性的生产生活必需品（含物质产品和服务产品等），如香烟、电信、铁路等仍为少数央企 靠政策进行垄断以外，绝大多数行业都有民营企业的身影，并且存在不同程度的竞争。随着 人均收入水平的不断提高, 廉价劣质产品正在逐渐失去市场, 越来越多的消费者更加关注产 品的质量, 愿意为高质量的产品支付较高的价格。在企业数量众多、市场竞争比较激烈的行 业, 已经形成买方市场, 过硬的产品质量是企业赢得竞争的关键。随着中国融入全球经济的 程度不断加深, 贸易壁垒不断降低, 进口品大量涌入, 来自国外产品的竞争也迫使国内企业 日益重视产品质量；对试图进入国际市场的企业而言，质量竞争显得更加重要。

产品质量不仅是产品的优劣程度和耐用程度，更是包括所有产品内在品质和外在特征的 综合, 包括使用性能、安全性、可靠性、可维修性等。产品质量提升不仅需要依靠管理, 更 需要依靠技术创新，技术创新能力成为企业能否在竞争中获胜的决定性因素。企业必须通过 技术创新提高产品的各项指标、改善用户使用体验或应用新技术生产差异化产品等。由于市 场经济起步较晚、知识产权保护意识不强等因素, 导致在很长一段时间内, 国内很多企业对 
技术创新不够重视, 研发投入总体偏低。近年来, 这种情况得到一定程度的改善, 部分企业 意识到研发的重要性, 持续的进行研发投入, 并取得了可喜的效果, 专利申请数量和质量都 有明显提高。但除了彩电、手机等少数行业经过充分竞争, 形成少数大企业把控市场的寡头 行业, 大部分国产产品要么产品要质量明显低于进口产品。企业想要提供高质量的产品, 通 常要么依靠全球采购进行组装, 要么购买欧美的先进技术设备进行生产。总之, 目前大多数 行业技术水平相对发达国家较低, 技术基础差、创新能力不强、缺乏核心技术。要解决技术 落后问题, 必须提高企业创新能力。创新能力的提高首先需要政府加强知识产权保护, 对侵 犯工业知识产权的行为依法进行严厉惩处, 消除外部性, 使企业能够获得研发投入带来的收 益, 其次是企业选择合适的创新路径进行技术创新。本文将通过对比分析国产汽车的技术创 新和市场业绩，来探讨不同创新路径对当前企业技术创新能力影响。

\section{2. 国内车企业绩及创新路径对比}

\section{1 业绩比较}

随着收入水平的提高, 家庭轿车逐渐普及, 国内汽车行业近年来得到迅速发展。中国乘 用车市场在2006-2016年间实现了稳步增长, 销量从517.6万辆逐步发展到2437.7万辆, 其中 2016年较2015年增长了14.9\%。在中国经济整体增速下降至6\%的背景下, 这一增长显得尤其 可贵。乘用车市场看似形式一片大好, 但并不是每家企业都获得可观的收益。表1是2016年各 大车企的利润及增幅情况, 其中上汽、一汽、长安、广汽和江铃等属于大型国企, 长城、比 亚迪、吉利属于民营企业。在八大车企公布的业绩预告中, 上汽集团虽然增长率不高, 但规 模最大, 销量648万辆, 利润超过 300 亿; 吉利汽车业绩增幅最亮眼, 利润 45.2 亿, 增幅 $100 \%$, 销量76.59亿, 增幅50\%（单车利润大幅提高）; 长城汽车利润 105.47 亿, 增幅 $30.87 \%$, 销量 107.45万辆, 增长 $26.01 \%$; 广汽集团55.02-65.5亿, 增幅30-55\%, 销量 165.7 亿, 增幅27\%; 而 作为“共和国长子”的一汽销量出现负增长, 其一汽夏利销量下降 $41.5 \%$, 一汽轿车亏损 9.45-9.7 亿, 销量下降-17.97\%。

从净利润总额看, 上汽一家独大, 但是从净利润同比增幅来看, 比亚迪和吉利分别为 89.11\%和100\%, 表现亮眼。比亚迪利润主要来自新能源车型, 而新能源车型主要依靠政府财 政补贴。新能源车的财政补贴在逐年降低, 2020年以后可能直接取消补贴, 因此比亚迪的业 绩可持续性存疑。吉利汽车的业绩是建立在新款普通车型销量扩大的基础之上的, 产品质量 和价格也都有明显提高, 2016年净利润提高 $100 \%$, 而销量只提高 $50 \%$, 达到 76.6 万辆, 单车 利润明显提高，2017年更是将销售目标定在100万辆。

表1 2016年各大车企利润情况

\begin{tabular}{|c|c|c|c|c|}
\hline 排名 & 车企 & $\begin{array}{c}2016 \text { 年净利润 } \\
\text { 亿元 }\end{array}$ & $\begin{array}{c}2015 \text { 年净利润 } \\
\text { 亿元 }\end{array}$ & $\begin{array}{c}\text { 同比增幅 } \\
\%\end{array}$ \\
\hline 1 & 上汽集团 & 320.28 & 297.94 & 7.5 \\
\hline 2 & 长城集团 & 105.5 & 80.59 & 30.87 \\
\hline 3 & 长安汽车 & $102-112$ & 99.53 & $2.48-12.53$ \\
\hline 4 & 比亚迪汽车 & 60.06 & 31.76 & 89.11 \\
\hline 5 & 广汽集团 & $55.02-65.6$ & 42.30 & $30-35$ \\
\hline 6 & 吉利汽车 & 45.2 & 22.60 & 100 \\
\hline 7 & 江铃汽车 & 13.18 & 22.22 & -40.69 \\
\hline 8 & 中国重汽 & $3.9-4.46$ & 2.79 & $40-60$ \\
\hline 9 & 一汽轿车 & $-9.45-9.7$ & 0.53 & --- \\
\hline 10 & 一汽夏利 & $1.55-1.95$ & 0.18 重组前 & -- \\
\hline
\end{tabular}

表格引自《2016年车企净利润榜出炉从你身上赚了多少钱》，搜狐网站新闻。 


\section{2 技术创新路径对比}

目前国内家轿市场竞争者主要有中外合资品牌、自主品牌和进口品牌等，其中合资品牌 长期占据重要地位, 自主品牌发力时间较晚。汽车工业被政府定调为支柱产业, 而当年国产 汽车技术太落后，且缺乏资金，政府对汽车行业实行 “市场换技术”，对汽车进口采取了严 厉的管制措施, 要求想进入中国市场的外国汽车厂商, 必须与中国企业设立合资企业, 在中 国国内生产。政策的初衷是想通过贸易保护，将国内市场与世界市场隔离开来，致使国内外 价格相差很大，从而提高对外国车企的吸引力，而合资生产则可以使中国企业在较短时间内 获得对方的先进技术。但事与愿违，一方面，外国车企不愿意分享先进技术，另一方面，长 期的贸易保护使得汽车市场利润丰厚，多数参与合资的国企，如一汽、东风、广汽等大型国 企, 在享受贸易保护带来的巨大蛋糕时, 忘记了学习对方技术, 也没有动力进行创新。因此, 一直到中国入世后若干年, 汽车行业仍旧波澜不惊。直到近几年汽车进口政策开始松动, 竞 争日益激烈，国内乘用车市场已经从卖方市场转变为卖方市场，并出现过剩产能，企业间的 竞争也不再是简单的价格竞争。各企业开始面临生存危机时, 竞争效应才迫使我国自主品牌 汽车进行真正意义上的技术创新。

对于国内民族汽车工业而言，技术远远落后于发到国家的车企，即便是经过几十年合资 生产，我们的国企如一汽、上汽和东风等也没学到核心技术，起步较晚的民营企业更是基础 普遍薄弱。因此，大多数中国车企的技术创新不外乎模仿、引进、消化、吸收，进而自主创 新的过程，但是随着国力不断增强，企业规模扩大，横向进行水平型跨国并购也成为一种靠 谱的选择。

自主品牌汽车选择了不同的创新路径。隶属芜湖国资委的奇瑞汽车，较早的提出自主创 新, 在研发方面做了大量投入, 并取得了较好的效果, 但近年来市场表现不佳。一汽是典型 的国企，财大气粗，红旗、夏利品牌经营多年，在研发方面投入巨资，本应遥遥领先，但是 推出的产品几乎无人问津，红旗企业甚至创下年销量不足 10 辆的战绩，令人唏嘘。上汽则是 相对成功的大型国有车企，在与大众、通用等巨头合资的同时，通过收购欧美车企，获得荣 威、名爵车企的品牌和技术, 其自主品牌在市场占有一席之地。比亚迪作为后起的民营车企, 凭借其电池领域的长期积累，在新能源汽车领域占有领先地位（相对其他自主品牌而言）, 靠政府对新能源车的补助，实现了客观的收益。而2016年迅速崛起的吉利汽车，同样是民营 企业，因收购了以安全性能著称的沃尔沃，借用沃尔沃的技术，成功开发出新的平台，再以 新平台开发新车型，如博瑞、博越、新帝豪等车型，一举获得市场认可，实现利润翻番。

从业绩看, 作为民营企业的吉利汽车表现最为突出, 究其原因是吉利收购沃尔沃之后, 更加重视研发，增加了在国内外的研发投入。据吉利汽车公司网站资料显示，“吉利汽车集团 在浙江杭州建有研究院，在中国上海、瑞典哥德堡、西班牙巴塞罗那、美国加州设立了造型 设计中心，构建了全球造型设计体系; 在瑞典哥德堡设立了吉利汽车欧洲研发中心 (CEVT), 打造具有全球竞争力的中级车模块化基础架构。”与沃尔沃在瑞典合作开发新平台 CMA和 $\mathrm{SPA}$ ，其中现 $\mathrm{C}$ 是紧凑级车、 $\mathrm{M}$ 是模块化、 $\mathrm{A}$ 是架构，就是基础架构模块。将基础的技术搭建 好, 然后再取进行不同的组合与衍生, 这是一种基础性的技术。沃尔沃与吉利共享该平台, 这样不仅有利于实现规模经济，降低成本，更提高了吉利汽车的技术水平。（沃尔沃协助吉 利开发新平台, 8款新车使用, http://auto.news18a.com/, 2015-6-1。) 此外, 吉利的在新车开 发时还直接由沃尔沃设计团队操刀, 吉利推出的首款中级轿车博瑞还采用沃尔沃的安全技术。 这样，在整合沃尔沃的技术资源之后，吉利汽车的性能和质量有了很大提升，轿车和SUV产 品都得到了越来越多的消费者认可，销量也随着博越、帝豪GL等新车的推出而实现快速增长。 长城汽车的突出表现也离不开技术支持，依靠 7000 人的研发团队，实现了不错的业绩，但是 严重依赖一款产品HAVAL H6, 其他产品销量惨淡, 轿车市场更是完全没有人气。一汽历史 相对较长，1950年开始建立，同时也享有先发优势，凭借政策优势与丰田、大众、马自达、 奥迪合资生产汽车，本应该技术实力最为雄厚，经验最为丰富，且研发投入不少，但业绩表 现不佳。 
因此，对于车企而言，自主开发固然是好，但在当前，需要想办法尽快将别人的技术变 成自己的技术。而核心技术难以抄袭, 像比亚迪等喜欢逆向开发的企业、众泰等直接照抄的 企业只能抄袭其整车或零部件的外观, 核心参数指标是无法获得的, 需要长期的经验积累。 合资生产的经历表明, 试图通过战略联盟方式, 获得外方的先进技术也是不可能的; 要想与 先进企业一起开发, 又却缺乏技术基础, 况且对方必然设法避免核心技术外泄。唯有通过跨 国并购才能在短期内帮助国内企业实现技术突破和飞跃。

\section{3. 结论及启示}

汽车厂商们选择了不同的技术创新路径, 提供了差异化的产品 (至少通过是通过公开的 模仿, 山寨了部分车型），部分企业在没有支付被抄袭方专利使用费的前提下，直接将别人 的成果借鉴过来，仿制外观相似的产品。在企业初期阶段，因技术能力弱、又无力投入巨资 进行研发, 而采取山寨的方式, 做法虽不可取, 但也可以理解, 如比亚迪仿制丰田、陆风仿 制路虎等; 也有专门山寨不思进取的, 如不能及时转型, 则难成大器, 如众泰。前者能够及 时转型, 进行自主研发, 尚有进步的空间, 后者则始终难登大雅之堂。奇瑞大概是唯一坚持 正向开发的中国车企, 虽然技术落后于外企, 但是经过多年积累, 在发动机、变速箱和整车 平台方面都取得了不错的成绩, 只是在经历短暂的辉煌之后, 泯然众人。目前看来, 通过并 购沃尔沃, 实现技术飞跃的吉利汽车实现了产品的升级换代, 品质价格双双提高, 有望更上 一层楼。显然, 通过跨国并购获取国外竞争对手的先进技术资源是吉利汽车取得成功的关键, 相对于仿制和技术引进而言, 效果更好。汽车行业的经验可以推广到很多行业, 我们可以得 到以下启示:

\section{1 政府层面}

自主品牌不仅可以通过跨国并购获得先进技术，还可以借此建立海外生产基地，利用被 收购方的销售渠道拓展国际市场。为此, 政府部门应提供必要的帮助

3.1.1 加强知识产权保护净化竞争环境

众所周知, 唯有加强知识产权保护，使企业能够享受创新带来的全部收益，企业才有动 力投入资源进行创新, 否则即使政府补贴再多, 企业也不愿意真正研发, 只会导致骗补行为 层出不穷, 地方政府的研发补贴对促进企业创新的激励效应并不明显（许培源, 2014）。政 府的职责应该是对各种产权进行有效保护，创造良好的竞争环境，促进企业间的公平竞争。 知识产权也是产权, 必须进行有效保护, 对侵权行为零容忍, 司法机关也应秉公执法, 不能 偏袙诉讼中的任何一方, 不能有地方保护意识。因此, 政府必须落实知识产权保护工作, 严 万打击侵权行为, 创造有益于即技术创新的法律环境。

3.1 .2 放松跨国并购的外汇管制

因担心外汇流失过快，防止资金外逃，目前政府对外汇使用进行了一定程度的管制，不 管是企业还是个人使用外汇都受到比较严格的管制。此举虽然在一定程度上减少了外汇的流 出, 但是误伤了那些希望通过对外直接投资拓展国际市场业务的企业。对于确实需要进行海 外投资、跨国并购的本土车企，应适当放松管制，保证正常的投资所需外汇。

\section{2 企业层面}

\subsection{1 收购或参股发达国家的车企}

通过跨国并购或战略联盟获得关键技术，迅速弥补技术差距。在众多技术密集型产业中， 要想迅速缩小与国外竞争对手的技术差距, 可以借鉴吉利的经验, 通过收购经营陷入困境的 竞争对手, 获取其技术资源, 包括也有技术积累和研发设施、技术人员等。如果能够进行有 效整合, 将其核心技术拿来, 必然能在较短时间内提升自己的技术水平和创新能力, 生产出 竞争力强的产品, 从而实现跳跃式发展。与技术领先的车企组建技术战略联盟, 共同开发特 定技术，也有助于我们获得新的知识和技术。 


\subsection{2 融入全球价值链}

在经济全球化程度不断提高的背景下, 本土车企当积极融入全球价值链, 在世界范围内 采购零部件。有一定实力的企业需要改变思维, 不再只是追求嵌入全球价值链, 我们也可以 成为集大成者, 一如国产智能手机。我们的企业技术提升后, 能够独立从事产品设计研发, 并建立知名度较高的品牌, 至于中间环节可以部分甚至全部外包出去: 可以进行全球采购自 行组装、也可以直接委托其他企业代工。这样, 就可以占据微笑曲线上利润较高的两端, 从 而获得更高的利润。

\section{References}

[1] Pei -yuan XU, Yan - bao ZHANG, Industrial technology characteristics, IPR and innovation, Studies in Science of Science, 2014(06):950-960.

[2] Xiao-yuan LIU, Song LIN, Innovation of Start-up Enterprises--Dual Perspectives of Technological Innovation Resource Allocation and Innovation Outputs, R\&D Management, 2013(05):12-25.

[3] Xian-ming Wu, Zhi-wen Su, The lever of transnational mergers and acquisitions as a technology catch-up: from the perspective of dynamic capabilities. Management World, 2014, (04)146-164.

[4] Fan-chen MENG, Hui MIAO, The Correlation Analysis between Cross-border M \& A and Corporate Technological Progress of China, Journal of Beijing Institute of Technology(Social Sciences Edition), 2010,(02)10-15.

[5] Lin FANG, Da-hai SONG, Cross- border M\&A VS Core Technology, Science of Science and Management of S. \& T, 2007,(02)136-141. 